\title{
Evaluation of cellulose substrates treated with Metarhizium anisopliae (Metschnikoff) Sorokin as a biological control agent against the termite Microcerotermes diversus Silvestri (Isoptera: Termitidae)
}

\begin{abstract}
This article is the first report on the promising effect of an entomopathogenic fungus, Metarhizium anisopliae (Metschnikoff) Sorokin to control populations of Microcerotermes diversus Silvestri. Biological control is an alternative to the long-term usage of chemical pesticides. M. anisopliae, the causal agent of green muscardine disease of insects, is an important fungus in biological control of insect pests. Bait systems can eliminate entire colonies of subterranean termites. Baiting reduces adverse environmental impacts caused by organochlorine and organophosphate pesticides in the control of termites and creates sustainable protection of buildings against their invasion. Treated-sawdust bait was applied by two methods: a) combination of treated sawdust and untreated filter paper, and b) combination of treated sawdust and untreated sawdust. When combinations of treated sawdust and untreated sawdust were used, $\mathrm{LC}_{50}$ and $\mathrm{LC}_{90}$ were $8.4 \times 10^{6}$ and $3.9 \times 10^{7}$ (spore/ml), respectively. With the use of improved bait formula and more virulent strains, we hope to achieve better control of termite colonies and enable pathogens to become a useful element in the Integrated Pest Management system.
\end{abstract}

Key words: termites, entomopathogenic fungus, biological control, sawdust, feeding.

\section{INTRODUCTION}

Microcerotermes diversus Silvestri (Isoptera: Termitidae) is an extremely destructive pest of wood and is considered to be the major termite species in Iran, Iraq and Oman. Methods for the control of termites, including chemical control, baiting system and wood protection, have hardly been investigated scientifically in Iran. Current management of subterranean termites in Iran mainly involves the application of a soil insecticide to reduce or isolate their foraging populations (Habibpour, 2006). In other parts of the world insecticidal baits have been shown to be an effective alternative to conventional soil insecticides for remedial termite control ( $\mathrm{Su}, 1991)$. Bait systems can eliminate entire colonies of subterranean termites ( $\mathrm{Su} \&$ Scheffrahn, 1996). Biological control is recognized as a realistic alternative to chemical pesticides (Bayon et al., 2000). The study of pathogens for termite control started as early as 1965 (Wang \& 
Powell, 2004). Metarhizium anisopliae (Metschnikoff) Sorokin, the causal agent of green muscardine disease of insects, is an important fungus in biological control of insect pests (Tajik Ghanbalani et al., 2009). Fungi exhibit qualities which can make them ideal for this application, including a slow-acting nature similar to that of successful chemicals, the ability to self replicate, and the ability of fungal spores to be spread by termite social behavior (Grace \& Zoberi, 1992). Baiting reduces adverse environmental impacts caused by organochlorine and organophosphate pesticides in the control of termites and creates sustainable protection of buildings against their invasion ( $\mathrm{Su}, 1991)$. Bait systems are composed of two parts: a) a slow-acting toxicant, and b) a nutritive substrate, such as sawdust, with absorbent additive materials (including sugars, nitrogenous compounds and pheromones). Foraging termites acquire slow-acting toxicants by feeding on the bait and then transfer it to other individuals in the colony through trophallaxis (Guadalupe \& Morales-Ramos, 2001). This study was conducted to examine the effect of the fungus $M$. anisopliae on the termite $M$. diversus.

\section{MATERIALS AND METHODS}

Collection of termites: Termites were collected from wooden blocks of beech (Fagus orientalis Lipsky) $\left(3 \times 6 \times 20 \mathrm{~cm}^{3}\right)$ placed in infected soil in Ahvaz (Iran). Worker termites were used for this experiment.

Fungal isolate: In this research $M$. anisopliae (DEMI 001) was used. The strain was originally isolated from Rhynchophorus ferrugineus Olivier (Coleoptera: Curculionidae) and stored at the Iranian Research Institute of Plant Protection.

Preparation of media: Fungi were cultured on Sabouraud Dextrose Agar with 1\% yeast extract medium. Petri dishes were placed in an incubator $\left(28 \pm 1^{\circ} \mathrm{C}\right.$ with $85 \pm 5 \%$ R.H.) for two weeks.

Preparation of fungal suspension: To prepare the fungal suspension, $1 \mathrm{ml}$ of polysorbate monoleate (Tween $80 \AA$ ) was added to $100 \mathrm{ml}$ sterile distilled water and spores were harvested from the media surface with a shallow scalpel cut and placed into the solution. Spore suspension concentration was determined using a Haemocytometer.

Experiment: After preliminary trials, concentrations of $1.1 \times 10^{5}, 2.7 \times 10^{6}, 3.7 \times 10^{7}$ and $3.5 \times 10^{8}$ (spore/ml) were selected for testing. Treated sawdust bait was applied by two methods: a) combination of treated sawdust and untreated filter paper, and b) combination of treated sawdust and untreated sawdust. a) In this test $2 \mathrm{~g}$ of sugarcane molasses and $2 \mathrm{~g}$ of agar mixed in $100 \mathrm{ml}$ of fungus spore suspension were used. This combination was placed in shaker for 30 minutes. Then $25 \mathrm{~g}$ of beech sawdust had been added and mixed well. At this stage the bait was ready for testing. Also pieces of filter paper (Whatman ${ }^{\circledR}$ cat No 100142 ) were used. The filter paper with a diameter of 42 $\mathrm{mm}$ cut into two halves and these pieces were used in this experiment. Four grams of 
bait were placed inside a plastic Petri dish together with a piece of filter paper in other side of the dish. The filter paper was moistened with sterile distilled water. b) In this method the bait was prepared as in the previous test and the same sawdust was prepared and sterile distilled water had been used instead of spore suspension. Four grams of bait were placed inside a Petri dish ( $9 \mathrm{~cm}$ diameter, $1 \mathrm{~cm}$ height) after weighing and $4 \mathrm{~g}$ of untreated sawdust was placed in the other side. One hundred worker termites were added into every Petri dish. Sterile distillated water was applied instead of spore suspension in control treatment. Four replications were carried out for every treatment. Petri dishes were incubated in $28 \pm 1{ }^{\circ} \mathrm{C}$ with $85 \pm 5 \%$ R.H. in the dark. The rate of mortality had been registered for 14 days. Analysis of variance performed by SAS (9.1). Graphs were drawn by software Excel 2007. Comparison of means calculated by LSD test at the 0.05 level.

\section{RESULTS}

The rate of $\mathrm{LC}_{50}$ and $\mathrm{LC}_{90}$ in both methods is summarized in Tab. 1. When combinations of treated sawdust and untreated sawdust was used in one Petri dish, $\mathrm{LC}_{50}$ and LC90 were $8.4 \times 10^{6}$ and $3.9 \times 10^{7}$ (spore $\left./ \mathrm{ml}\right)$, respectively $(\mathrm{df}=14, \mathrm{~F}=23$ and $\mathrm{p}<0.0001$ ). Also when combination of treated sawdust and untreated filter paper was used in one Petri dish, $\mathrm{LC}_{50}$ and $\mathrm{LC}_{90}$ were $4.8 \times 10^{6}$ and $3.3 \times 10^{7}$ (spore $\left./ \mathrm{ml}\right)$, respectively $(\mathrm{df}=14$, $\mathrm{F}=13$ and $\mathrm{p}<0.0001$ ) (Tab. 1).

The rate of $\mathrm{LT}_{50}$ and $\mathrm{LT}_{90}$ in both methods is summarized in Tab. 2. In both techniques the rate of $\mathrm{LT}_{50}$ and $\mathrm{LT}_{90}$ were decreased with increasing concentration of spore suspension in bait. The lowest level of $\mathrm{LT}_{50} \mathrm{LT}_{90}$ related to the concentration of $3.5 \times 10^{8}$ (spore $/ \mathrm{ml}$ ) in both methods that over $90 \%$ of the population were killed in less than a week. When filter paper was applied instead of sawdust in untreated section, the rate of $\mathrm{LT}_{50}$ and $\mathrm{LT}_{90}$ were low (Tab. 2).

The mean comparisons of termites mortality with the two methods is reported in Fig. 1. The highest mortality was observed with concentrations of $3.7 \times 10^{7}$ and $3.5 \times 10^{8}$

\begin{tabular}{|c|c|c|c|c|}
\hline Baits & $\begin{array}{c}\mathbf{L C}_{\mathbf{5 0}} \text { (Spore/ml) } \\
\mathbf{9 5 \%} \text { Fiducial limits) }\end{array}$ & $\begin{array}{c}\mathbf{L C}_{\mathbf{9 0}} \text { (Spore/mI) } \\
\mathbf{( 9 5 \% \text { Fiducial limits } )}\end{array}$ & $\mathbf{F}$ & Estimate \pm SE \\
\hline $\mathrm{SS}^{*}$ & $8.4 \times 10^{6}\left(6.2 \times 10^{6}-1.0 \times 10^{7}\right)$ & $3.9 \times 10^{7}\left(1.1 \times 10^{7}-9.8 \times 10^{7}\right)$ & 23 & $1.92 \pm 1.09$ \\
\hline $\mathrm{SF}^{* *}$ & $4.8 \times 10^{6}\left(2.8 \times 10^{6}-8.2 \times 10^{6}\right)$ & $3.3 \times 10^{7}\left(1.8 \times 10^{7}-9.0 \times 10^{7}\right)$ & 13 & $1.52 \pm 0.21$ \\
\hline
\end{tabular}

Tab. 1 - The rate of $\mathrm{LC}_{50}$ and $\mathrm{LC}_{90}$ in both methods. * Treated sawdust and untreated sawdust. ** Treated sawdust and untreated filter paper. 


\begin{tabular}{|c|c|c|c|}
\hline $\begin{array}{c}\text { Concentration } \\
\text { (Spore/ml) }\end{array}$ & Baits & $\begin{array}{c}\text { LT }_{50} \text { (day) } \\
\text { (95\% Fiducial limits) }\end{array}$ & $\begin{array}{c}\text { LT }_{90} \text { (day) } \\
\text { (95\% Fiducial limits) }\end{array}$ \\
\hline \multirow{2}{*}{$1.1 \times 10^{5}$} & $\mathrm{SS}^{*}$ & $671(213-7262)$ & $10695(1659-519581)$ \\
\hline & $\mathrm{SF}^{* *}$ & $344(142-1874)$ & $3759(876-61282)$ \\
\hline \multirow{2}{*}{$2.7 \times 10^{6}$} & SS* & $96(55-263)$ & $666(247-4104)$ \\
\hline & $\mathrm{SF}^{* *}$ & $24.75(22.24-28.26)$ & $73.22(59-96.10)$ \\
\hline \multirow{2}{*}{$3.7 \times 10^{7}$} & $\mathrm{SS}^{*}$ & $5.02(4.66-5.37)$ & $13.39(12.15-15.03)$ \\
\hline & $\mathrm{SF}^{* *}$ & $3.84(3.46-4.22)$ & $10.23(9.21-11.61)$ \\
\hline \multirow{2}{*}{$3.5 \times 10^{8}$} & $\mathrm{SS}^{*}$ & $2.85(2.63-3.07)$ & $6.14(5.66-6.74)$ \\
\hline & $\mathrm{SF}^{* *}$ & $2.42(2.33-2.5)$ & $4.68(4.51-4.88)$ \\
\hline
\end{tabular}

Tab. 2 - The rate of $\mathrm{LT}_{50}$ and $\mathrm{LT}_{90}$ in both methods.

* Treated sawdust and untreated sawdust . ** Treated sawdust and untreated filter paper.

(spore/ml). The rate of mortality was enhanced by increasing the concentration of spore suspension in the bait. There was no significant difference between concentrations of $3.7 \times 10^{7}$ and $3.5 \times 10^{8}$ (spore $/ \mathrm{ml}$ ). The lowest level of mortality (less than $10 \%$ ) was observed with concentration of $1.1 \times 10^{5}$ (spore $\left./ \mathrm{ml}\right)$. The level of mortality with concentration of $2.7 \times 10^{6}($ spore $/ \mathrm{ml})$ was less than $10 \%$ in combination of treated sawdust and untreated sawdust and was less than $30 \%$ in combination of treated sawdust and untreated filter paper (Fig. 1).

The mean comparisons of feeding in combination of treated sawdust and untreated filter paper method is reported in Fig. 2. The highest level of feeding was achieved from

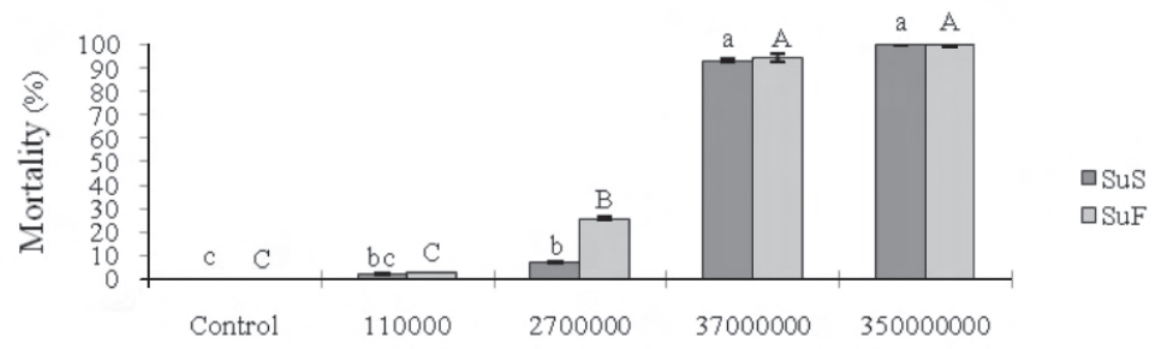

Treatment (Spore/ml)

Fig. 1 - Comparison of mean mortality in both methods. The same letter above bars indicates absence of significant differences (LSD test, $\mathrm{p}=0.05$ ). * SuS: Treated sawdust and untreated sawdust. ** SuF: Treated sawdust and untreated filter paper. 


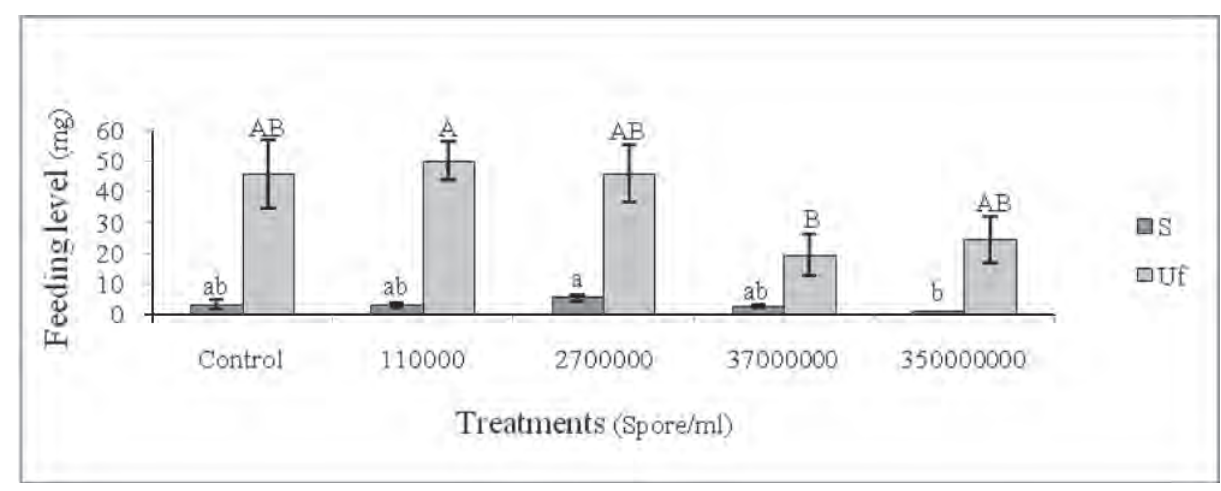

Fig. 2 - Comparison of mean feeding in combination of treated sawdust and untreated filter paper method. The same letter above bars indicates absence of significant differences (LSD test, $\mathrm{p}=$ $0.05) .{ }^{*} \mathrm{~S}$ : Treated sawdust. ** Uf: Untreated filter paper.

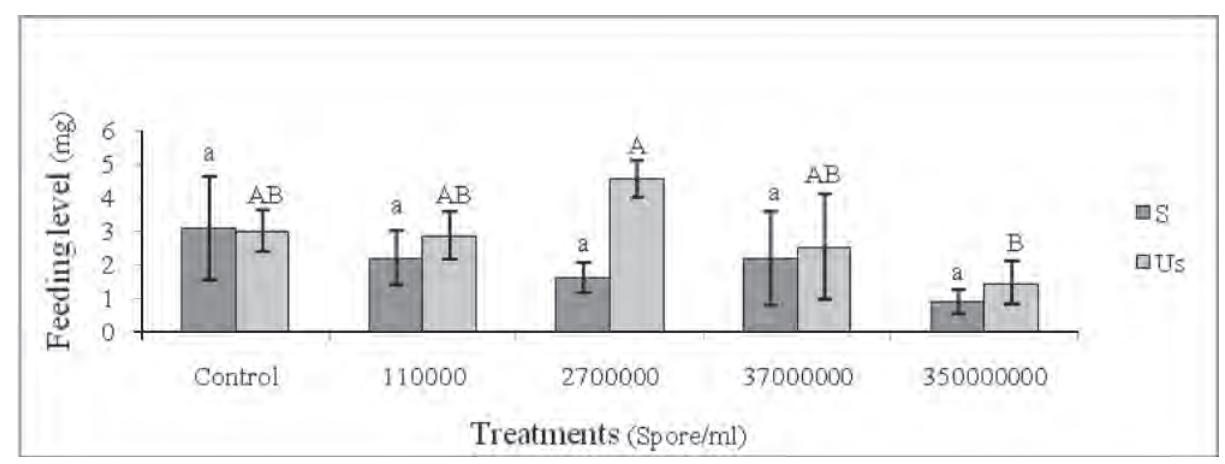

Fig. 3 - Comparison of mean feeding for combination of treated sawdust and untreated sawdust method. The same letter above bars indicates absence of significant differences (LSD test, $\mathrm{p}=$ $0.05) .{ }^{*}$ S: Treated sawdust. ** Us: Untreated sawdust

combination treated sawdust in concentration of $2.7 \times 10^{6}($ spore $/ \mathrm{ml})$ that didn't exhibit significant different with control treatment and concentrations of $1.1 \times 10^{5}$ and $3.7 \times 10^{7}$ (spore $/ \mathrm{ml})$. But there was significant different with concentration of $3.5 \times 10^{8}(\mathrm{spore} / \mathrm{ml})$ and were placed on a higher level. The highest feeding activity occurred in concentration of $1.1 \times 10^{5}$ (spore/ml) from filter paper (Fig. 2).

The mean comparisons of feeding for combination of treated sawdust and untreated sawdust method is reported in Fig. 3. No significant different was detected from treated part. Furthermore, there were no significant different between rate of feeding from 
untreated sawdust in different concentrations except concentration of $3.5 \times 10^{8}$ (spore/ $\mathrm{ml}$ ) which was lower than the other. Overall rate of feeding was less in treated part than in the untreated part in all concentrations (Fig. 3)

\section{DISCUSSION AND CONCLUSIONS}

When combination of untreated sawdust was applied as untreated part, $\mathrm{LC}_{50}$ and $\mathrm{LC}_{90}$ exhibited higher level in comparison of untreated filter paper. Probably this is because of the higher attractiveness of a sawdust bait for termite than the filter paper. Comparison between $\mathrm{LC}_{50}$ and $\mathrm{LC}_{90}$ prepared acceptable information about performance of bait in different concentrations. The rate of $\mathrm{LC}_{50}$ and $\mathrm{LC}_{90}$ decreased with increasing concentration and due to lower level of these two parameter when untreated filter paper used instead of untreated sawdust. Mean comparisons of mortality revealed the importance of choosing the appropriate concentration in both methods. Collectively no significant different observed between rates of mortality in every concentration in two methods. Figs. 2 and 3 offer considerable information regarding the amount of eaten untreated and treated parts. According to Fig. 3 it can be expressed that termites feed less from treated baits. However, it should not be assumed that fungi are repellent for termites in high concentration and that the termites avoided the bait containing fungi. It should be noted that population of termites did decreas regarding to the rate of $\mathrm{LC}_{50}$ and $\mathrm{LC}_{90}$ in both methods in less than a week. Probably the reason of lower feeding rate in high concentrations with comparison of control and lower concentrations is related to this case. Wang \& Powell (2004) declared that M. anisopliae was not repellent for Reticulitermes flavipes Kollar (Iso.: Rhinotermitidae) and Coptotermes formosanus Shiraki (Iso.: Rhinotermitidae) in cellulose powder bait with effective concentrations. They suggested use of attractive baits as a suitable alternative for increasing performance of fungi against these two implanted termites. Habibpour et al. (2006) in research about laboratory evaluation of chemical additives as feeding stimulants for $M$. diversus represented that additive nitrogenous compounds such as Lesitin may increase efficacy of toxicant baits against termites in field condition. Using of such cases may increase efficacy of entomopathogenic fungi against of termites. Habibipour et al. (2008) applied borax-treated bait against of $M$. diversus and exploded that level of mortality and rapid of mortality of $M$. diversus depend on toxin concentration that was according to the present study. Collectively this research investigated possibility of using entomopathogenic fungus $M$. anisopliae in form of bait against $M$. diversus and trying to raise awareness of performance of this fungus. According to this findings fungus in combination of sawdust bait revealed efficient alternative in vitro and therefore it can be a candidate for optimizing performance and field trials. It may take a long treatment period and many treatment sites to eliminate field colonies using $M$. anisopliae. Most field studies failed to eliminate termite colonies by using fungal pathogens. These failed experiences had prevented the fungus from becoming a stand-alone termite treatment measure. Developing a palatable formulation with appropriate concentration is the key to improve its efficacy. With the study of improved bait formula and virulent 
strains, we hope to achieve better control of termite colonies and enable pathogens to become a useful element in the Integrated Pest Management system.

\section{ACKNOWLEDGEMENTS}

This research was supported by Shahid-Chamran University of Ahvaz, Iran.

\section{REFERENCES}

Bayon I.L., Ansard D., Brunet C., Girardi S., Paulmier I., 2000 - Biocontrol of Reticulitermes santonensis by entomopathogenic fungi improvement of the contamination Process. The in IRG/WP/DOC 00-10359, 14-19 May.

Grace J.K., Zoberi M.H., 1992 - Experimental evidence for transmission of Beauveria bassiana by Reticulitermes flavipes workers (Isoptera: Rhinotermitidae). Sociobiology, 20: 23-28.

Guadalupe R.M., Morales-Ramos J.A. 2001 - Bait matrix for delivery of chitin synthesis in hibitors to the Formosan subterranean termites (Isoptera: Rhinotermitidae). Journal of Economic Entomology, 94 (2): 506-510.

HabibPour B., 2006 - Laboratory and field evaluation of bait-toxicants for suppression subterranean termite populations in Ahvaz (Iran). PhD Dissertation, Department of Plant Protection, College of Agriculture, Shahid-Chamran University, Ahvaz, Iran.

Habibpour B., Mossadegh M.S., Moharramipour S., 2006 - Laboratory evaluation of chemical additives as feeding stimulants for Microcerotermes diversus Silvestri (Isoptera: Termitidae). The Scientific Journal of Agriculture, 29 (2): 33-42.

Habibpour B., Mossadegh M.S., Moharramipour S., Fathi M., 2008 - Toxicity of borax bait to Microcerotermes diversus (Silvestri) (Isoptera: Termitidae) under laboratory conditions. Journal of Knowledge of Agriculture, 18 (4): 171-185.

Su N.Y., 1991 - Evaluation of bait-toxicants for suppression of subterranean termite populations. Sociobiology, 19: 211-220.

Su N.Y., SchefrRAHN R.H., 1996 - Fate of subterranean termite colonies (Isoptera) after bait applications - an update and review. Sociobiology, 23: 253-275.

Tajick Ghanbalani M.A., Asgharzadeh A., Hadizadeh A.R., Mohammadi Sharif M., 2009 - A quick method for Metarhizium anisopliae isolation from cultural soils. American Journal of Agricultural and Biological Science, 4 (2): 152-155.

Wang C., Powell J.E., 2004 - Cellulose bait improves the effectiveness of Metarhizium anisopliae as a microbial control of termites (Isoptera: Rhinotermitidae). Biological Control, 30: 523-529.

Behzad Habibpour, Department of Plant Protection, College of Agriculture, Shahid-Chamran University of Ahvaz, Iran.

E-mail: habibpour_b@scu.ac.ir

Amir Cheraghi, Department of Plant Protection, College of Agriculture, Shahid-Chamran University of Ahvaz, Iran.

Mohammad SAeed Mossadegh, Department of Plant Protection, College of Agriculture, Shahid Chamran University of Ahvaz, Iran. 